PAPER

\title{
Long term effects of bilateral subthalamic nucleus stimulation on cognitive function, mood, and behaviour in Parkinson's disease
}

\author{
A Funkiewiez, C Ardouin, E Caputo, P Krack, V Fraix, H Klinger, S Chabardes, K Foote, \\ A-L Benabid, P Pollak
}

J Neurol Neurosurg Psychiatry 2004;75:834-839. doi: 10.1136/jnnp.2002.009803

See end of article for authors' affiliations

.....................

Correspondence to:

Dr P Krack, Department of

Clinical and Biological

Neurosciences, Service de

Neurologie, Centre

Hospitalier Universitaire de

Grenoble, BP 217, 38043

Grenoble Cedex 9

France; paul.krack@

ujf-grenoble.fr

Received

26 December 2002

Revised 25 July 2003

Accepted 23 August 2003

\begin{abstract}
Background: Long term effects of subthalamic nucleus (STN) stimulation on cognition, mood, and behaviour are unknown.

Objective: This study evaluated the cognitive, mood, and behavioural effects of bilateral subthalamic nucleus deep brain stimulation (STN DBS) in patients with Parkinson's disease (PD) followed up for three years.

Methods: A consecutive series of 77 PD patients was assessed before, one, and three years after surgery. Mean (SD) age at surgery was 55 (8). Seven patients died or were lost for follow up. Neuropsychological assessment included a global cognitive scale, memory, and frontal tests. Depression was evaluated using the Beck depression inventory. Assessment of thought disorders and apathy was based on the unified Parkinson's disease rating scale. Reports of the behavioural changes are mainly based on interviews done by the same neuropsychologist at each follow up.

Results: Only two cognitive variables worsened (category fluency, total score of fluency). Age was a predictor of decline in executive functions. Depression improved whereas apathy and thought disorders worsened. Major behavioural changes were two transient aggressive impulsive episodes, one suicide, four suicide attempts, one permanent apathy, one transient severe depression, four psychoses (one permanent), and five hypomania (one permanent).

Conclusions: Comparing baseline, one year, and three year postoperative assessments, STN stimulation did not lead to global cognitive deterioration. Apathy scores mildly increased. Depression scores mildly improved. Behavioural changes were comparatively rare and mostly transient. Single case reports show the major synergistic effects of both medication and stimulation on mood and behaviour, illustrating the importance of a correct postoperative management.
\end{abstract}

whether observed changes are related to the surgical intervention, to changes in medication, or to the stimulation itself. In addition, long term follow up must take into account the evolution of the disease. An alternative way to more specifically study the effects of STN DBS on cognition and mood is to compare the patients' performances with their stimulators turned on or off. Studies using this methodology have shown that stimulation can improve some executive functions, with improved scores on the trail making test, random generation test, Wisconsin card sorting test and graphic series. ${ }^{51}$ Working memory was also improved with STN stimulation. ${ }^{5}$ On the other hand, visual conditional learning was impaired by STN stimulation and patients made a greater number of errors on the interference condition of the Stroop test with stimulation on. ${ }^{21}$ Acute changes of mood, specifically related to stimulation have also been reported. An assessment of acute subjective psychic effects of STN DBS has shown psychic stimulation, euphoria, and increased motivation, with decreased fatigue, anxiety, and tension when stimulators are turned on. ${ }^{22}{ }^{23}$ Hilarity has been described related to an increase in stimulation parameters. ${ }^{24}$

Abbreviations: STN DBS, subthalamic deep brain stimulation; PD, Parkinson's disease; WCST, Wisconsin card sorting test; MDRS, Mattis dementia rating scale; BDI, Beck depression inventory; UPDRS, unified Parkinson's disease rating scale
Comparisons of preoperative and postoperative cognitive function or mood do not permit the determination of 
The aim of this study was to assess the long term cognitive, mood, and behavioural effects of bilateral STN DBS in a large consecutive series of patients operated in the same centre.

\section{METHOD \\ Patients}

From the whole series operated on so far, we examined the initial consecutive series of 77 parkinsonian patients (34 women) who had been operated on at least three years previously. Of this series, 70 have been followed up for three years. Among the seven excluded patients, four patients have been lost to follow up, two have died (one suicide, one death from unrelated disease), and one patient who developed a large frontal haematoma during surgery could not be evaluated. A systematic postoperative MRI showed four haematomas and three contusions. All seven patients had cognitive deterioration, either transient (2) or permanent (5). Two of these patients with permanent cognitive deteriorations could not be followed up. The mean (SD) age at surgery was $55(8)$ and the mean (SD) duration of disease at surgery was 15 (5) years. The mean STN stimulation induced motor improvement was $63 \%$ one year after surgery and 59\% three years after surgery (unified Parkinson's disease rating scale (UPDRS) part III, on-stimulation/off-medication compared with preoperative off-medication), with a decrease in dopaminergic medication of $67 \%$ either one or three years after surgery.

\section{Neuropsychological, mood, and behavioural assessments}

Global cognitive efficiency was assessed with the Mattis dementia rating scale (MDRS). ${ }^{25}$ Executive functions were assessed with the Wisconsin card sorting test (WCST) ${ }^{26}$ We analysed the number of categories, the number of perseverative errors, the maintaining errors (that is, when the correct criterion is lost by the patient), and the total number of errors. Category and literal fluency (number of words in one minute) and graphic and motor series (score out of 10) were also assessed. A global frontal score was calculated from these four measures, with a maximum score of $50 .{ }^{27}$ Verbal learning was evaluated with the Grober and Buschke test. ${ }^{28}$ We prospectively considered the UPDRS part $\mathrm{I}^{29}$ scores to assess psychosis (thought disorders, item 2) and apathy (motivation/initiation, item 4). These scores range from 0 (without any symptoms), to 4 (severe symptoms). Mood was assessed with the Beck depression inventory (BDI), ${ }^{30}$ scores range from 0 to 59, divided into four categories: 0 (no depression, scores from 0 to 9), l (mild depression, scores from 10 to 17), 2 (moderate depression, scores from 18 to 24), and 3 (severe depression, scores from 25 to 59). This neuropsychological battery has been described in detail previously. ${ }^{4}$ We used different versions for the following tests: the WCST, ${ }^{5}$ fluency (categories and letters were changed following Cardebat equivalences, ${ }^{31}$ ) and for the Grober and Buschke learning test. The MDRS, the BDI, and the Grober and Buschke tests were not used preoperatively for the first patients, moreover the Grober and Buschke test can be used only in French speaking patients. In addition to the neuropsychological tests battery and UPDRS I, we also collected history based data concerning clear cut psychiatric events. The description of behavioural changes was mainly based on a systematic open interview done by the same neuropsychologist (CA) in all patients before surgery, at three months, one, two, and three years after surgery or when needed. All available information from the medical files and the caregivers were also taken into account. The diagnosis of hypomania has been carried out following DSM-IV criteria. Clinical diagnoses of apathy was based on the definition of Marin. ${ }^{32}$ Whereas the definition of apathy according to Marin excludes the presence of depression or dementia, the UPDRS I apathy item does not take into consideration comorbidity. Illustrative changes in mood or behaviour are presented as case reports.

\section{Procedure}

Most patients were assessed without levodopa before surgery $(83 \%)$. One year after surgery, all the patients have been evaluated with STN stimulation turned on, without levodopa in $94 \%$ of patients at one year and $69 \%$ at three years after surgery.

\section{Statistical analysis}

Analysis of variances for repeated measures were used to compare neuropsychological performances before, one year, and three years after STN DBS, and Pearson's test for correlations. Post hoc comparisons (Fisher's PLSD) were then used when analysis of variance was significant to compare data two by two. Because of the number of cognitive variables (24), we applied the Bonferroni correction, with a significance at $\mathrm{p}<0.01$.

\section{RESULTS}

Table 1 lists the results of the neuropsychological test battery. Five variables changed significantly between preoperative and postoperative data (shown in bold type in the table). Category fluency was diminished on postoperative evaluation. Post hoc comparisons showed that the differences between preoperative score and one year $(p<0.0001)$ and three years after surgery $(\mathrm{p}=0.001)$ are significant (but not the comparison between one and three years after surgery). The total number of words cited by patients (category and literal fluency) varied also significantly between the three assessments. Post hoc comparisons showed that the scores are significantly worse one year $(p=0.0011)$ and three years $(p=0.0006)$ after surgery, when compared with the preoperative score, but the difference between one year and three years after surgery is not significant.

The BDI was significantly improved between the three assessments. Post hoc comparisons revealed that the comparison between preoperative and one year $(\mathrm{p}<0.0001)$ and three years $(p=0.004)$ were significant. The distribution of patients among the four categories of depression and the percentages of changes are shown in table 1 and table 2 . The number of patients with severe depression at three years was the same as at baseline. Half of these patients with severe depression at three years were already severely depressed at baseline.

The UPDRS I scores of thought disorders significantly worsened with years $(\mathrm{p}<0.001)$. Post hoc comparisons revealed that differences were significant only between before surgery and three years after $(p=0.001)$, and between one and three years $(p=0.007)$. However, there were only three patients with a score $\geqslant 2$ before surgery and one year after surgery and only six patients three years after surgery, showing that only few patients had clinically relevant thought disorders. This increasing score, although significant, mainly represents increases between score 0 to 1 , no score of 4 (representing psychosis) was noted at any assessments.

Apathy score changed significantly $(p=0.005)$, showing an increasing proportion of apathetic patients with time. Post hoc comparisons showed that only the difference between the score at baseline and at three years is significant $(p=0.001)$, although there was a trend for the comparison between baseline and one year after surgery $(p=0.055)$. The proportion of patients with a score $\geqslant 2$ doubled one year after surgery, from $8.7 \%$ before surgery to $17.4 \%$ one year after surgery and $24.6 \%$ three years after surgery. 
Table 1 Cognitive efficiency, memory, mood, and behavioural scores (mean (SD)) before, one year, and three years after STN DBS

\begin{tabular}{|c|c|c|c|c|c|}
\hline & & Before surgery & $\begin{array}{l}\text { One year after } \\
\text { surgery }\end{array}$ & $\begin{array}{l}\text { Three years after } \\
\text { surgery }\end{array}$ & $\begin{array}{l}\text { Analysis of variance } \\
p=\end{array}$ \\
\hline Mattis DRS & $(n=66)$ & & & & \\
\hline total score & & $136.8(4.9)$ & $135.9(6.9)$ & 134.6 (11.2) & 0.072 \\
\hline attention & & $35.8(0.9)$ & $35.9(1.1)$ & $35.5(1.3)$ & 0.017 \\
\hline initiation & & $34.0(3.6)$ & $32.6(4.7)$ & $32.5(5.3)$ & 0.036 \\
\hline construction & & $6.0(0.2)$ & $5.9(0.2)$ & $5.8(0.8)$ & 0.207 \\
\hline conceptualisation & & $37.2(2.2)$ & $37.1(2.1)$ & $36.8(3.1)$ & 0.442 \\
\hline memory & & $23.9(1.2)$ & $24.1(1.5)$ & $23.7(2.9)$ & 0.443 \\
\hline Wisconsin CST & $(n=69)$ & & & & \\
\hline number of categories & & $5.1(1.2)$ & $5.0(1.4)$ & $5.0(1.6)$ & 0.384 \\
\hline total errors & & $7.3(5.3)$ & $7.5(6.1)$ & $7.2(6.2)$ & 0.752 \\
\hline perseverative errors & & $2.2(2.0)$ & $2.4(2.9)$ & 0.373 & \\
\hline maintaining errors & & $1.1(1.4)$ & $1.3(1.8)$ & $1.3(2.0)$ & 0.909 \\
\hline Lexical fluency & $(n=69)$ & & & & \\
\hline category & & $14.4(3.8)$ & $12.6(3.7)$ & $12.7(3.9)$ & $<0.001$ \\
\hline literal & & $11.9(4.3)$ & $11.1(4.9)$ & $10.8(5.2)$ & 0.149 \\
\hline total & & $26.2(7.0)$ & $23.7(7.3)$ & $23.5(7.8)$ & 0.001 \\
\hline Series & $(n=69)$ & & & & \\
\hline graphic & & $7.8(2.4)$ & $7.8(2.6)$ & $7.7(2.9)$ & 0.816 \\
\hline motor & & $8.6(2.2)$ & $8.6(2.4)$ & $8.0(3.1)$ & 0.138 \\
\hline \multirow{2}{*}{ Frontal score } & $(n=69)$ & & & & \\
\hline & & $41.0(7.5)$ & $39.6(9.0)$ & $38.8(10.5)$ & 0.042 \\
\hline Grober and Buschke verbal learning test & $(n=51)$ & & & & \\
\hline free recall & & $28.7(6.1)$ & $28.5(7.3)$ & $27.8(8.4)$ & 0.479 \\
\hline total recall & & $46.0(2.8)$ & $46.2(2.3)$ & $45.7(3.7)$ & 0.384 \\
\hline delayed free recall & & $10.9(2.6)$ & $10.1(2.9)$ & $10.5(3.1)$ & 0.391 \\
\hline delayed total recall & & $15.7(0.7)$ & $15.7(0.8)$ & 15.5 (1.3) & 0.168 \\
\hline recognition & & $15.7(0.9)$ & $15.6(1.0)$ & $15.5(1.1)$ & 0.150 \\
\hline \multirow{6}{*}{$\begin{array}{l}\text { Beck depression inventory } \\
\text { global score } \\
\text { categories of depression: } \\
\text { absence (0-9) } \\
\text { mild (10-17) } \\
\text { moderate (18-24) } \\
\text { severe (25-59) }\end{array}$} & $(n=60)$ & & & & \\
\hline & & $15.4(7.2)$ & $11.5(7.4)$ & $12.6(8.6)$ & 0.001 \\
\hline & & $n=12$ & $\mathrm{n}=27$ & $\mathrm{n}=28$ & \\
\hline & & $n=28$ & $n=21$ & $n=23$ & \\
\hline & & $n=14$ & $n=10$ & $n=3$ & \\
\hline & & $n=6$ & $\mathrm{n}=2$ & $n=6$ & \\
\hline UPDRS I & $(n=69)$ & & & & \\
\hline item 2 (thought disorders) & & $0.1(0.4)$ & $0.3(0.6)$ & $0.4(0.7)$ & $<0.001$ \\
\hline item 4 (apathy) & & $0.5(0.8)$ & $0.9(0.8)$ & $0.9(1.1)$ & 0.005 \\
\hline
\end{tabular}

Three other variables showed a tendency to be impaired after surgery: two subscores of the Mattis DRS: attention and initiation scores (respectively $\mathrm{p}=0.017$ and $\mathrm{p}=0.036$ ) and the frontal score $(\mathrm{p}=0.042)$.

\begin{tabular}{|c|c|c|c|c|}
\hline & & Improvement (\%) & No change (\%) & Decline (\%) \\
\hline Mattis DRS & $(n=66)$ & & & \\
\hline total score & & 1.5 & 90.9 & 7.6 \\
\hline attention & & 7.6 & 75.7 & 16.7 \\
\hline initiation & & 9.1 & 71.2 & 19.7 \\
\hline Wisconsin CST & $(n=67)$ & & & \\
\hline number of categories & & 9.0 & 76.1 & 14.9 \\
\hline total errors & & 13.4 & 77.6 & 9.0 \\
\hline Lexical fluency & $(n=69)$ & & & \\
\hline category & & 2.9 & 63.8 & 33.3 \\
\hline literal & & 4.3 & 79.7 & 16.0 \\
\hline Series & $(n=69)$ & & & \\
\hline graphic & & 14.5 & 69.6 & 15.9 \\
\hline motor & & 10.2 & 76.8 & 13.0 \\
\hline Frontal score & $(n=69)$ & & & \\
\hline & & 10.1 & 68.2 & 21.7 \\
\hline $\begin{array}{l}\text { Grober and Buschke verbal } \\
\text { learning test }\end{array}$ & $(n=51)$ & & & \\
\hline free recall & & 11.8 & 68.6 & 19.6 \\
\hline delayed free recall & & 7.8 & 74.5 & 17.7 \\
\hline Beck depression inventory & $(n=60)$ & & & \\
\hline $\begin{array}{l}\text { global score } \\
\text { categories of depression: }\end{array}$ & & 16.7 & 76.6 & 6.7 \\
\hline absence (0-9) & & - & 75.0 & 25.0 \\
\hline mild (10-17) & & 50.0 & 42.9 & 7.1 \\
\hline moderate (18-24) & & 85.7 & 0.0 & 14.3 \\
\hline severe $(25-59)$ & & 50.0 & 50.0 & - \\
\hline
\end{tabular}


A significant correlation has been found between the decrease in the frontal score $(p<0.001)$, the initiation subtest of the Mattis $(p=0.007)$, and the preoperative age of patients. The correlation between the preoperative age of patients and the item 2 of the UPDRS I, thought disorders tended to be significant $(\mathrm{p}=0.023)$. None of these variables correlated with the preoperative Mattis score. Correlation between apathy and fluency (category) scores was significant one year after surgery $(p=0.002)$ and tended to be significant three years after surgery $(\mathrm{p}=0.023)$.

Table 2 shows the patterns of changes for the main variables. Most of the patients remained cognitively stable by most measures. Among the 13 principal variables, the percentage of patients whose performance did not change from before to three years after surgery varied from $64 \%$ to $91 \%$ (see table 2). Only nine patients of 66 had a MDRS score below 130, the threshold for dementia, three years after surgery. Five of the nine had already scores below 130 before surgery. We can relate cognitive impairments to intracerebral bleeding or contusion in two patients. The two other patients showed a progressive deterioration of cognition between baseline and three years after surgery.

Concerning psychiatric events it is quite difficult to evaluate their percentage because of the non-standardised collection of data. After surgery, we noted four suicide attempts and one patient died by suicide. This occurred at different time points after surgery $(2,3,5,6$, and 36 months).

Hypomania occurred in five patients, always during the first three months after surgery. Four of these patients recovered spontaneously an adapted behaviour within a few weeks, this behaviour persisted periodically during three years in one patient. Two patients had an episode of impulsive aggressive behaviour in the first postoperative days. One patient already had a tendency to react in an impulsive way before surgery. This episode happened after an increase in stimulation parameters and he was fully oriented throughout this episode. In the second patient, the behaviour occurred in association with postoperative delirium. At different times after surgery, four patients suffered from psychosis. One patient had a transient florid psychosis six weeks after surgery that required hospitalisation. Another patient had permanent psychosis, hallucinations or delusions without insight occurred in the two other ones. Two of these three last patients were demented. Severe depression requiring transient hospitalisation occurred in one patient.

\section{CASE REPORTS \\ Case report 1: apathy or loss of psychic autoactivation}

A 56 year old man had a 24 year history of PD with severe akinesia off-drug and a craving behaviour. On levodopa (3700 mg daily) he was dyskinetic, and his relatives related hypersexuality. Evaluation revealed mild depression and no apathy. Three months postoperatively, his off-period motor signs and his dyskinesia were considerably improved. Levodopa was decreased to $1000 \mathrm{mg}$. However, the patient did not recognise his dramatic motor improvement in offmedication condition; in contrast, he claimed that he had globally worsened, complaining of fatigue, and worsened anxiety. He had no initiative, but enjoyed seeing his grandson. Hypersexuality had disappeared. Despite major apathy, his depression was only slightly worse than before surgery. Fluoxetine and amitriptyline treatment failed. Found motionless on his bed during hospitalisation, the patient was asked why he stayed in bed. He responded, "I am taking no medication. I am off". After explanation that with STN stimulation activated he could move around without levodopa, he was profoundly doubtful, but did rise and walked normally on command. He described his state: "Something around me must move to turn me on. I need something to motivate $\mathrm{me}^{\prime \prime}$. Over the next five years, medication and stimulation parameters remained stable. His motor state was identical at each visit. Although his apathy mildly improved and was stable at each annual visit, fatigue remained his main complaint. He was able to do everything, but he remained dependent on external stimuli.

\section{Case report 2: depression sensitive to dopaminergic treatment}

A 59 year old man had a 17 year history of akinetic-rigid PD with motor, and concurrent mood fluctuations on levodopa (2050 mg daily). Soon after disease onset, he developed mania with hypersexuality while on bromocriptine $(75 \mathrm{mg})$. Withdrawing medication provoked depression. Preoperative depression was mild. At 12 month follow up, his treatment comprised: monopolar stimulation parameters-left $2.6 \mathrm{~V}$, $60 \mu \mathrm{s}, 130 \mathrm{~Hz}$, right $2.4 \mathrm{~V}, 60 \mu \mathrm{s}, 130 \mathrm{~Hz}$, and levodopa $(600 \mathrm{mg})$. With this treatment he had no residual motor symptoms and his mood was normal. Then, dopaminergic treatment was stopped. Six weeks later he reported depressed feelings that subsequently evolved to suicidal thoughts. He started antidepressant treatment with venlaflaxine $(150 \mathrm{mg}$ ) and resumed low dose levodopa (200 mg). Stimulation parameters were not changed. Suicidal thoughts disappeared, but he remained depressed during the following three months. He stopped taking venlaflaxine, as he experienced no benefit, and resumed bromocriptine. His mood rapidly normalised on a small dose of dopaminergic treatment (15 mg bromocriptine and $200 \mathrm{mg}$ of levodopa). Both his motor state and mood remained stable for the next two years with no further changes in treatment.

\section{Case report 3: disappearance of mood fluctuations}

A 61 year old woman had a 22 year history of severe PD with disabling motor fluctuations and drug induced dyskinesia. Preoperative levodopa was $1100 \mathrm{mg}$ daily. Her mood fluctuated concurrently with her motor symptoms, and she received regular electroconvulsive therapy at six week intervals to improve her mood. Depression was absent at the time of surgery, but she felt deeply sad during each off period. Postoperatively the patient's nonmotor fluctuations disappeared and mood was normal. She regained a very active social life during the following years. At her three year follow up, treatment included levodopa $(450 \mathrm{mg})$, monopolar stimulation parameters-right side $3.6 \mathrm{~V}, 90 \mu \mathrm{s}, 185 \mathrm{~Hz}$ and left side $3.2 \mathrm{~V}, 90 \mu \mathrm{s}, 185 \mathrm{~Hz}$. When stimulation was deactivated for motor evaluation, the patient immediately felt overwhelming sadness, dissolved into tears, and experienced a progressive reappearance of severe parkinsonism. When describing the impact of treatment, she said, "If stimulation is switched off, I am dead; when on, I am alive. With medication on top, it's happiness and well being".

\section{Case report 4: postoperative honeymoon or hypomania}

This 43 year old man had a 17 year history of PD with severe motor fluctuations on levodopa treatment $(750 \mathrm{mg})$. The preoperative assessment found moderate depression. He viewed surgery as his only recourse because his quality of life was so diminished. At the postoperative three month assessment, he had major motor improvement and no need for antiparkinsonian medication. He described an independent, depression free life. He had, however, been hyperactive with very little sleep during those three months. He said, "I never before had such energy, neither motor nor intellectually. I rediscovered the joie de vivre, pleasure, laughter". He compared this state with his honeymoon at the onset of action of levodopa: "With drugs, I had lost control; it was not 
joy but a drunkenness, a very short euphoria, which was not my own..." At the 12 month assessment he remained medication free with the same stimulation parameters. He described his immediate postoperative euphoric state: "It was too much. I had too much energy in me. I wasn't able to sleep for three months, I had to keep moving all the time...but it felt so good to be euphoric, it was like a liberation after 17 years of sickness".

\section{DISCUSSION}

This analysis of long term follow up data suggests that there is no global deterioration in neuropsychological function attributable to bilateral STN DBS itself. This confirms previous reports with shorter follow up durations. ${ }^{14511}$ Postoperative mild cognitive decline related to the surgical procedure is mostly transient. Permanent cognitive decline related to the surgical procedure occurred in five patients in our series. A very progressive decline occurred in two other patients, probably related to the evolution of the neurodegenerative process. One of the two demented patients also exhibited psychotic behaviour. Age of patients was significantly correlated with the decrease in frontal score, in keeping with the more frequent incidence of parkinsonian frontosubcortical dementia with age..$^{33-35}$

Some limitations of this study need to be pointed out. Behaviour has not been assessed prospectively using psychiatric scales. Nevertheless, the same neuropsychologist has seen all patients at all the follow up times, with a complete interview, which provides a strong database. PD is a neuropsychiatric disease and moreover psychiatric complications of levodopa treatment are not rare ${ }^{36} 37$ Except for the cognitive deterioration occurring in some patients related to neurosurgical complications and for a slight increase in apathy, major psychiatric events were comparatively rare. However, as the study lacks a control group it is difficult to draw any firm conclusions concerning the frequency of such complications related to the treatment. Another problem is the test-re-test effect. Indeed, a learning effect could have masked a deterioration in some of the neuropsychological tests. Nevertheless, we used different versions when possible. The proportion of patients with increasing scores with time did not exceed $13 \%$. Nevertheless we cannot totally exclude some learning effects.

The diminished verbal fluency described previously ${ }^{4} 89$ is corroborated at long term follow up. It seems to occur immediately after surgery, with no further deterioration over time, thus it could be non-specifically related to surgery itself or to decrease in medication that is maximal immediately after surgery. Although this change in fluency is significant, its magnitude is minor. Verbal fluency tasks may be less externally guided than other executive tests. ${ }^{5}$ In our study, the observed verbal fluency deficit could be related to a decrease in self activation. In other words, it may be a result of the increased apathy commonly seen in association with the decrease in dopaminergic treatment after STN DBS. ${ }^{9} 2038$ Indeed there is a correlation between high levels of apathy and low category fluency scores one year after surgery, and a trend for correlation three years after surgery.

One of the most intriguing symptoms observed after surgery was apathy. This apathy, which often is expressed as a fatigue by the patient, is best illustrated by case report 1 . The patients are neither depressed nor demented. When discussing with them, they express they do not feel sad, have many plans and that they wish to do a lot of things, but that they feel tired and have difficulties in starting any actions. The caregivers typically report that although they are able to do everything, in fact they stay sitting in a chair all day long without taking any initiative. When told to do a job however, they will carry out this task, and can enjoy doing them afterwards. This seems to correspond to the syndrome described by Laplane in basal ganglia lesions and called loss of psychic self activation. ${ }^{39}$ This syndrome obviously escapes to detection using the neuropsychological test battery that we applied except for fluency as discussed above. How can we explain this apathy? Apathy is associated with lesions of the limbic basal ganglia loop, mainly projecting to the anterior cingulate cortex. Total loss of initiative was described after bilateral cingulate vascular lesions ("akinetic mutism"), or bilateral GPi lesions ("loss of psychic self activation"). The decrease in striatal dopaminergic activity can also lead to an apathetic state such as in PD or after neuroleptic treatment. This suggests that apathy can be improved by increasing dopaminergic activity in the limbic basal ganglia loop, or by modulating this loop. Our study shows that parkinsonian patients can develop apathy after bilateral STN DBS effective on off-period motor function. Therefore, STN stimulation may be less effective than a dopaminergic treatment to control the parkinsonian apathetic state. Actually, dopaminergic drugs are known to improve the parkinsonian apathy ${ }^{41}$ and an acute levodopa challenge has been shown to be more effective on the subjective psychic stimulation than bilateral STN stimulation. ${ }^{42}$ This finding can help the practical postoperative management of patients with bilateral STN DBS. A state of apathy should be carefully searched and preferentially treated by increasing or resuming dopamine drugs, even if this treatment is not required to control parkinsonian motor symptoms. In that case, dopaminergic agonists drug are generally preferred to levodopa to avoid the risk of dyskinesia. ${ }^{43}$

In this series there was a mild but significant improvement in depression, even three years after surgery, confirming similar findings in the immediate postoperative period. ${ }^{42}$ It seems, however, that while patients do indeed feel better in the early postoperative period, over time their mood scores tend to progressively rise close to preoperative values. This favourable effect on mood has already been shown after short term STN stimulation. ${ }^{24}{ }^{42}$ Short duration changes in mood have not been evaluated in our study. Mood frequently fluctuates along with motor swings. ${ }^{44}$ In single cases mood fluctuations disappeared with STN stimulation (case report 3). Future studies should investigate the effect of subthalamic stimulation on mood fluctuations using more appropriate tests.

Although average changes in mood were not impressive, in some patients major changes in initiative, mood, or behaviour occurred, as illustrated in case reports. These changes were mostly transient and could be influenced by changes in medication or stimulation.

In the literature, some single cases of mania, ${ }^{13-15}$ or depression $^{16-19}$ have been reported after STN DBS. These opposite changes are only seemingly contradictory. Hypomania or mania generally occurs in the immediate postoperative period as in our cases and can be explained by additive psychotropic effects of STN stimulation and dopaminergic treatment. ${ }^{42} 45$ Decreasing long acting dopamine agonist drugs before surgery may help prevent postoperative hypomania. Depression on the other hand can appear with a longer latency and can be related to decrease in dopaminergic treatment and the loss of the antidepressant effect of levodopa in the same way as for apathy. ${ }^{41} 4245$ Adapting medication and stimulation parameters would avoid such complications in the long term. ${ }^{46}$

The occurrence of impulsive aggressive behaviour and suicide attempts is intriguing. This is reminiscent of the premature responses described after STN lesioning in rats. ${ }^{47}$ In some patients, especially those with psychiatric history, ${ }^{18}$ changing the STN neuronal activity by DBS may trigger an impulsive behaviour. Aggressive behaviour has been 
explained by current diffusion to the hypothalamus by other authors. ${ }^{48}$

Considering the architecture of the cortical-subcortical circuitry, ${ }^{49}$ several data suggest that STN DBS may influence the associative and limbic loops in addition to the motor loop. ${ }^{21} 23244245$ Although this study did not include a comprehensive assessment of all aspects of cognitive function, the comparative lack of cognitive changes observed on long term postoperative follow up suggests that the influence of STN DBS on the associative loop is minor and much less important than its effect on the motor loop.

In conclusion, long term bilateral STN stimulation does not seem to have a global significant effect on neuropsychological functions and mood despite its important effect on off-period motor function. However, individual cases may exhibit pronounced changes in mood and behaviour. The risk of psychiatric complications can be reduced by a careful management of pharmacological and stimulation treatments.

\section{Authors' affiliations}

A Funkiewiez, C Ardouin, P Krack, V Fraix, H Klinger, S Chabardes, K Foote, A-L Benabid, P Pollak, Department of Clinical and Biological Neurosciences, Joseph Fourier University, Grenoble, France

E Caputo, Department of Neurology, Ospedale San Paolo, Milan, Italy

Competing interests: $P K, A B$, and $P P$ have been reimbursed by Medtronic, the manufacturer of the implanted material for attending several conferences. $A B$ is the director of the research laboratory $U 318$ at INSERM France, which receives from Medtronic an unrestricted education grant. PP has received an honorarium from Medtronic for expert work.

\section{REFERENCES}

1 Limousin $\mathrm{P}$, Krack $\mathrm{P}$, Pollak $\mathrm{P}$, et al. Electrical stimulation of the subthalamic nucleus in advanced Parkinson's disease. N Engl J Med 1998;339:1 105-1 1.

2 The Deep-Brain stimulation for Parkinson's Disease Study Group. Deep-

brain stimulation of the subthalamic nucleus or the pars interna of the globus pallidus in Parkinson's disease. N Engl J Med 2001;345:956-63.

3 Woods SP, Fields JA, Troster Al. Neuropsychological sequelae of subthalamic nucleus deep brain stimulation in Parkinson's disease: a critical review. Neuropsychol Rev 2002;12:111-26.

4 Ardouin C, Pillon B, Peiffer E, et al. Bilateral subthalamic or pallidal stimulation for Parkinson's disease affects neither memory nor executive functions: a consecutive series of 62 patients. Ann Neurol 1999;46:217-23.

5 Pillon B, Ardouin C, Damier P, et al. Neuropsychological changes between "off" and "on" STN or GPi stimulation in Parkinson's disease. Neurology 2000;55:411-18.

6 Dujardin K, Defebvre L, Krystkowiak P, et al. Influence of chronic bilateral stimulation of the subthalamic nucleus on cognitive function in Parkinson's disease. J Neurol 2001;248:603-11.

7 Perozzo P, Rizzone M, Bergamasco B, et al. Deep brain stimulation of the subthalamic nucleus in Parkinson's disease: comparison of pre- and postoperative neuropsychological evaluation. J Neurol Sci 2001;192:9-15.

8 Saint-Cyr JA, Trepanier LL, Kumar R, et al. Neuropsychological consequences of chronic bilateral stimulation of the subthalamic nucleus in Parkinson's disease. Brain 2000;123:2091-108.

9 Trepanier LL, Kumar R, Lozano AM, et al. Neuropsychological outcome of GPi pallidotomy and GPi or STN deep brain stimulation in Parkinson's disease. Brain Cogn 2000;42:324-47.

10 Hariz MI, Johansson F, Shamsgovara $P$, et al. Bilateral subthalamic nucleus stimulation in a parkinsonian patient with preoperative deficits in speech and cognition: persistent improvement in mobility but increased dependency: a case study. Mov Disord 2000; 15:136-9.

11 Alegret M, Junque C, Valldeoriola F, et al. Effects of bilateral subthalamic stimulation on cognitive function in Parkinson disease. Arch Neurol 2001;58:1223-7.

12 Volkmann J, Allert N, Voges J, et al. Safety and efficacy of pallidal or subthalamic nucleus stimulation in advanced PD. Neurology 2001:56:548-51.

13 Kulisevsky J, Berthier ML, Gironell A, et al. Mania following deep brain stimulation for Parkinson's disease. Neurology 2002;59:1421-4.

14 Romito LM, Raja M, Daniele A, et al. Transient mania with hypersexuality after surgery for high frequency stimulation of the subthalamic nucleus in Parkinson's disease. Mov Disord 2002;17:1371-4.

15 Herzog J, Reiff J, Krack P, et al. Manic episode with psychotic symptoms induced by subthalamic nucleus stimulation in a patient with Parkinson's disease. Mov Disord 2003; 18:1382-4.

16 Berney A, Vingerhoets F, Perrin A, et al. Effect on mood of subthalamic DBS for Parkinson's disease A consecutive series of 24 patients. Neurology 2002;59:1427-9
17 Doshi PK, Chhaya N, Bhatt MH. Depression leading to attemped suicide after bilateral subthalamic nucleus stimulation for Parkinson's disease. Mov Disord 2002;17:1084-5.

18 Houeto JL, Mesnage V, Mallet L, et al. Behavioural disorders, Parkinson's disease and subthalamic stimulation. I Neurol Neurosurg Psychiatry 2002;72:701-7.

19 Thobois S, Mertens P, Guenot M, et al. Subthalamic nucleus stimulation in Parkinson's disease: clinical evaluation of 18 patients. J Neurol 2002;249:529-34

20 Krack P, Pollak P, Limousin P, et al. Subthalamic nucleus or internal pallidal stimulation in young onset Parkinson's disease. Brain 1998;121:451-7.

21 Jahanshahi $M$, Ardouin CM, Brown RG, et al. The impact of deep brain stimulation on executive function in Parkinson's disease. Brain 2000; 123:11 142-54.

22 Funkiewiez A, Ardouin C, Krack P, et al. Acute psychic effects of bilateral subthalamic nucleus stimulation in Parkinson's disease [abstract]. Mov Disord 2000;15(suppl 3):52.

23 Schneider F, Habel U, Volkmann J, et al. Deep brain stimulation of the subthalamic nucleus enhances emotional processing in Parkinson disease. Arch Gen Psychiatry 2003;60:296-302.

24 Krack P, Kumar R, Ardouin C, et al. Mirthful laughter induced by subthalamic nucleus stimulation. Mov Disord 2001;16:867-75.

25 Mattis S. Dementia rating scale: professional manual. Odessa, FL: Psychological Assessment Resources, 1988.

26 Nelson HE. A modified card sorting test sensitive to frontal lobe defects. Cortex 1976;12:313-24.

27 Pillon B, Dubois B, Lhermitte F, et al. Heterogeneity of cognitive impairment in progressive supranuclear palsy, Parkinson's disease, and Alzheimer's disease. Neurology 1986;36:1179-85.

28 Grober E, Buschke H. Genuine memory deficits in dementia. Developmental Neuropsychology 1987;3:13-36.

29 Fahn S, Elton, RL, members of the U. P.D.R.S. development commitee unified Unified Parkinson's disease rating scale. In: Fahn S, Marsden CD, Calne P, et al, eds. Recent development in Parkinson's disease. Florham Park, NJ: McMillan Health Care Information, 1987; 2:153-64.

30 Beck AT, Ward CH, Mendelson M, et al. An inventory for measuring depression. Arch Gen Psychiatry 1961;4:561-77.

31 Cardebat D, Doyon B, Puel $M$, et al. [Formal and semantic lexical evocation in normal subjects. Performance and dynamics of production as a function of sex, age and educational level]. Acta Neurol Belg 1990;90:207-17.

32 Marin RS. Differential diagnosis and classification of apathy. Am J Psychiatry 1990; 147:22-30.

33 Mayeux R, Stern Y, Rosenstein R, et al. An estimate of the prevalence of dementia in idiopathic Parkinson's disease. Arch Neurol 1988;45:260-2.

34 Aarsland D, Tandberg E, Larsen JP, et al. Frequency of dementia in Parkinson disease. Arch Neurol 1996;53:538-42.

35 Lieberman AN. Point of view: dementia in Parkinson's disease. Parkinsonism and Related Disorders 1997;3:151-8.

36 Riley DE, Lang AE. The spectrum of levodopa-related fluctuations in Parkinson's disease. Neurology 1993;43:1459-64.

37 Agid Y, Arnulf I, Beijani BP, et al. Parkinson's disease is a neuropsychiatric disorder. Adv Neurol 2003;91:365-70.

38 Funkiewiez A, Caputo E, Ardouin C, et al. Behavioral and mood changes associated with bilateral stimulation of the subthalamic nucleus: a consecutive series of 98 parkinsonian patients. [abstract]. Neurology 2001;56/suppl 2):49.

39 Laplane D, Baulac M, Pillon B, et al. [Loss of psychic self-activation. Compulsive activity of obsessional type. Bilateral lenticular lesion (author's translation)]. Rev Neurol 1982;138:137-41.

40 Laplane D, Baulac M, Widlocher D, et al. Pure psychic akinesia with bilateral lesions of basal ganglia. J Neurol Neurosurg Psychiatry 1984;47:377-85.

41 Maricle RA, Nutt JG, Valentine RJ, et al. Dose-response relationship of levodopa with mood and anxiety in fluctuating Parkinson's disease: a doubleblind, placebo-controlled study. Neurology 1995;45:1757-60.

42 Funkiewiez A, Ardouin C, Krack P, et al. Acute psychotropic effects of bilateral subthalamic nucleus stimulation and levodopa in Parkinson's disease. Mov Disord 2003; 18:524-30.

43 Moro E, Scerrati M, Romito LM, et al. Chronic subthalamic nucleus stimulation reduces medication requirements in Parkinson's disease. Neurology 1999:53:85-90.

44 Witjas T, Kaphan E, Azulay JP, et al. Nonmotor fluctuations in Parkinson's disease: frequent and disabling. Neurology 2002;59:408-13.

45 Krack P, Ardouin C, Funkiewiez A, et al. What is the influence of subthalamic nucleus stimulation on the limbic loop? In: Kultes-llinsky K, llinsky I, eds. Basal ganglia and thalamus in health and movement disorders. New York: Kluwer ganglia and thalamus in health and
Academic/Plenum, 2001:333-40.

46 Krack P, Fraix V, Mendes A, et al. Postoperative management of subthalamic nucleus stimulation for Parkinson's disease. Mov Disord 2002;17:S188-97.

47 Baunez C, Nieoullon A, Amalric M. In a rat model of parkinsonism, lesions of the subthalamic nucleus reverse increases of reaction time but induce a dramatic premature responding deficit. J Neurosci 1995;15:6531-41.

48 Beijani BP, Houeto JL, Hariz M, et al. Aggressive behavior induced by intraoperative stimulation in the triangle of Sano. Neurology 2002;59:1425-7

49 Alexander GE, DeLong MR, Strick PL. Parallel organization of functionally segregated circuits linking basal ganglia and cortex. Annu Rev Neurosci 1986;9:357-81. 